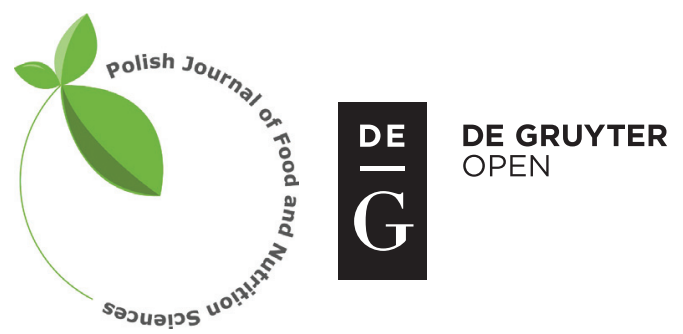

Pol. J. Food Nutr. Sci., 2017, Vol. 67, No. 3, pp. 219-224

DOI: $10.1515 /$ pjfns-2016-0027 http://journal.pan.olsztyn.pl

Original research article

Section: Nutritional Research

\title{
Effect of High Methionine and Folic Acid Diet on the Level of Homocysteine and Lipid Profile in Experimental Rats
}

\author{
Renata Bieżanowska-Kopeć*, Teresa Leszczyńska \\ Department of Human Nutrition, Faculty of Food Technology, \\ Agricultural University of Krakow, 30-149 Krakow, Balicka 122, Poland
}

Key words: methionine, folic acid, homocysteine, lipid profile, rats

The aim of this study was to reduce the level of homocysteine (Hcy) by high-methionine dietary supplementation of folic acid and to evaluate changes in lipid parameters in blood serum of experimental rats.

The animals were randomly divided into seven groups $(n=6$, male), and were fed seven different diets for 52 days. The rodents were fed with the AIN-93G semi-synthetic diet (group I), supplemented with $32 \mathrm{~g}$ of methionine/kg diet (group II), whereas groups III-VII were fed with AIN-93G semi-synthetic diet supplemented with $32 \mathrm{~g}$ of methionine $/ \mathrm{kg}$ diet and 2, 4, 8, 18 and $28 \mathrm{~g}$ of folic acid/ $\mathrm{kg}$ diet, respectively. Contents of of homocysteine, total cholesterol level, HDL fraction and triacylglycerols were assessed enzymatically in rats serum. In addition, the LDL +VLDL cholesterol content was calculated.

Folic acid content in the diet was found to be highly negatively correlated with homocysteine content $(\mathrm{r}=-0.95)$ and negatively correlated with triacylglycerols content $(r=-0.94)$ in the serum of rats. In the serum of rats which were fed the methionine diet with the highest-folic acid supplementation (28 mg folic acid/kg diet), homocysteine and triglyceride contents were significantly lower, compared to animals fed other types of experimental diets.

\section{INTRODUCTION}

Cardiovascular diseases (CVDs) are a serious problem in the public health all over the world. They are the main cause of death globally. The WHO estimated that 17.5 million people died from CVDs in 2012, representing 31\% of the global death rate [WHO, 2015]. According to the WHO, the most important risk factors of heart disease are an unhealthy diet, physical inactivity, tobacco use and harmful use of alcohol. The effects of behavioural risk factors are: hypertension, diabetes, hyperlipidaemia, overweight and obesity [WHO, 2015]. Hyperlipidemia and hyperhomocysteinemia are the major risk factors of CVDs [Obeid \& Herrmann, 2009]. A high risk of coronary heart diseases results from a low level of high-density lipoprotein (HDL) cholesterol, associated with a high level of low-density lipoprotein (LDL) cholesterol [Chien et al., 2007].

Homocysteine (Hcy), derived from methionine demethylation due to a biological reaction, belongs to sulfuric amino acids formed in the metabolic pathway of methionine/ Hcy. When the methionine supply from the diet is adequate, the formed Hcy undergoes catabolic transformations; a surplus of Hcy leads to hyperhomocysteinemia. The results of research proved that $2 / 3$ of hyperhomocysteinemia cases

\footnotetext{
* Corresponding Author: E-mail: r.biezanowska-kopec@ur.krakow.pl (R. Bieżanowska-Kopeć, PhD)
}

at humans are connected with a high consumption of meat and milk products (the products rich in methionine) with parallel deficiency of $\mathrm{B}_{12}, \mathrm{~B}_{6}$ vitamins and folic acid in the diet [Karakuła et al., 2009; Orzechowska-Pawitojć et al., 2005]. An increased homocysteine concentration in blood is an independent factor responsible for not only cardiovascular diseases [Hainaut et al., 2002; Herrmann et al., 2004; Selhub, 2008] but also other pathological cases occurring in a group of elderly people [Selhub, 2008]. Homocysteine is responsible for oxidation of the LDL cholesterol accelerating the development of the atherosclerotic plaques [Sierakowska-Fijałek et al., 2008] and influences the processes of blood clotting by adhesion of blood platelets to the vascular endothelium [Karakuła et al., 2009; Refsum et al., 2004]. On the other hand, methionine has an increasing effect on HDL-cholesterol and a decreasing effect on VLDL-cholesterol.

There are two crucial factors which have an effect on the reduction of homocysteine; these are the sufficient consumption and adequate nutritional status in relation to folates [Williams \& Schalinske, 2010]. The literature describes several experiments which proved an increased Hcy level in serum due to diet supplementation with methionine [Liu et al., 2013; Sharma et al., 2007]. The process of homocysteine re-methylation requires an adequate supply of folic acid, vitamin $\mathrm{B}_{1}$ and vitamin $\mathrm{B}_{6}$ [Bieżanowska-Kopeć et al., 2007; Liu et al. 2008]. There is a lack of research that would assess the relationship between a high consumption of methionine, taking into account its negative as well as positive impact on 
the development of atherosclerosis, and the supply of different doses of folic acid.

The aim of this study was to reduce the level of homocysteine (Hcy) by high-methionine dietary supplementation of folic acid and to evaluate changes in lipid parameters in blood serum of experimental rats, assuming the same beneficial effects on lipid metabolism of methionine.

The following research hypotheses were adopted:

1) High intake of methionine in the diet increases the concentration of homocysteine in the serum of experimental animals and changes parameters of the lipid profile.

2) Concurrent, high dietary intake of methionine and folic acid has a beneficial effect on the changes in the concentration of homocysteine and parameters of blood serum lipid profiles.

3) Changes in the concentration of homocysteine and lipid profile parameters in the blood serum are determined by the ingested dose of folic acid.

\section{MATERIALS AND METHODS}

The studies were carried out with 42 growing albino Wistar rats, purchased from the Animal Husbandry in Brwinów, Warsaw, Poland. Before the experiment, the animals were acclimatized for 4 days on standard laboratory chow. The four-week-old rodents, with their starting body weight being 117-136 g, were divided into seven groups $(n=6$, male). The division was made on the basis of their body weight in order to obtain similar group averages, i.e. $127( \pm 9) \mathrm{g}$. The animals were housed separately in stainless steel metabolic cages (temp. $23 \pm 2^{\circ} \mathrm{C}$ with a normal day/night cycle). During the experimental period (52 days), the control group (I) was fed with the AIN-93G semi-synthetic diet [Reeves, 1993], the second control group (II) was fed with the AIN-93G semi-synthetic diet supplemented with $32 \mathrm{~g}$ of methionine/kg diet, whereas groups III-VII were fed with the AIN-93G semi-synthetic diet supplemented with $32 \mathrm{~g}$ of methionine/ $\mathrm{kg}$ diet and 2, 4, 8, 18 and $28 \mathrm{~g}$ of folic acid/kg diet, respectively (Table 1 ).

The dose of methionine was chosen based on our earlier experiment, as was previously described [Bieżanowska-Kopeć \& Leszczyńska, 2012]. During the experiment, rodents were fed diets at $10 \%$ of the rat's body weight and had free access to water. The intake of diets was recorded every day. Body weight gain was recorded during the whole experiment on a weekly basis. At the end of the experiment, the animals were anesthetized with sodium thiopental (Biochemie, Vienna, Austria). The experiment was performed after receiving the agreement from the First Local Ethical Committee on Animal Testing at the Jagiellonian University in Krakow (Poland) and in accordance with the requirements of that organization. Blood samples were then collected via heart puncture into plain test tubes from animals under anesthesia. Blood samples were collected to obtain serum by centrifugation $(1500 \times g, 15 \mathrm{~min})$. The level of serum homocysteine was determined using in $v i$ tro immunoenzymatic tests (Immulite Homocysteine LKHO1, Llanberis, UK). Serum total cholesterol (TC) and HDL fraction were analyzed enzymatically with commercial kits (BioVendor cat.-no 10851, Czech Republic and BioVendor cat.-no 10855, Czech Republic). Triacylglycerols content was determined enzymatically with standard kits (BioVendor cat.-no 12805, Czech Republic). Lipid profile was determined using the COBAS INTEGRAL 400/700/800 apparatus. The level of the LDL+VLDL fraction was calculated as the difference between the total cholesterol level and the HDL fraction level.

Results were expressed as the mean value \pm standard deviation. Where appropriate, the data were subjected to a one-way ANOVA test (Statistica 9.0. package, Stat Soft, Inc., Tulsa, Oklahoma USA) followed by a post-hoc Duncan's

TABLE 1. Composition of experimental purified diets.

\begin{tabular}{|c|c|c|c|c|c|c|c|}
\hline \multirow{3}{*}{ Composition } & \multicolumn{7}{|c|}{ Diet } \\
\hline & I - control & $\begin{array}{l}\text { II - control with } \\
\text { methionine }\end{array}$ & III & IV & V & VI & VII \\
\hline & \multicolumn{7}{|c|}{$\mathrm{g} / \mathrm{kg}$ diet } \\
\hline Corn starch & 532.486 & 500.486 & 500.484 & 500.482 & 500.478 & 500.468 & 500.458 \\
\hline Sucrose & 100.00 & 100.00 & 100.00 & 100.00 & 100.00 & 100.00 & 100.00 \\
\hline Casein & 200.00 & 200.00 & 200.00 & 200.00 & 200.00 & 200.00 & 200.00 \\
\hline Alphacellulose & 50.00 & 50.00 & 50.00 & 50.00 & 50.00 & 50.00 & 50.00 \\
\hline Soybean oil & 70.00 & 70.00 & 70.00 & 70.00 & 70.00 & 70.00 & 70.00 \\
\hline Choline bitartrate $^{1}$ & 2.500 & 2.500 & 2.500 & 2.500 & 2.500 & 2.500 & 2.500 \\
\hline Tert-butylhydroquinone ${ }^{1}$ & 0.014 & 0.014 & 0.014 & 0.014 & 0.014 & 0.014 & 0.014 \\
\hline L-Methionine $^{1}$ & - & 32 & 32 & 32 & 32 & 32 & 32 \\
\hline Mineral mix ${ }^{2}$ & 35.00 & 35.00 & 35.00 & 35.00 & 35.00 & 35.00 & 35.00 \\
\hline Vitamin mix $^{3}$ & 10.00 & 10.00 & 10.00 & 10.00 & 10.00 & 10.00 & 10.00 \\
\hline Folic acid supplemented & 0 & 0 & 0.002 & 0.004 & 0.008 & 0.018 & 0.028 \\
\hline
\end{tabular}

1 - Sigma-Aldrich Sp. z o.o., Poznań, Polska, 2 - AIN-93G-MX [Reeves et al., 1993]; ${ }^{3}$ - AIN-93G-VX [Reeves et al., 1993 ]. 
multiple range test. The differences between treatment means were considered significant at $\mathrm{p} \leq 0.05$.

\section{RESULTS AND DISCUSSION}

\section{Homocysteine}

In this experiment, the rats fed the diet with $32 \mathrm{~g}$ methionine/kg (group II) showed a higher homocysteine content of about $709 \%$ compared to the control group I. The statistical analysis revealed that only in group VII receiving the diet with $28 \mathrm{mg}$ folic acid $/ \mathrm{kg}$, a decrease in Hcy concentration was significant $(p<0.05)$ in comparison with the control group I. Compared with the methionine-supplemented group II, the addition of folic acid in groups III to VII had no significant impact on the value of this parameter (Table 2).

In an organism, methionine supplied with food may undergo conversion to homocysteine through demethylation [Williams \& Schalinske, 2010]. Methionine in high concentrations participates in transformations of lipoproteins, exerts an influence on the exceeded level of HDL cholesterol [Bieżanowska-Kopeć \& Leszczyńska, 2012], however it simultaneously leads to increased Hcy concentrations in blood. According to Oda [2006], sulfur-containing amino acids are recognized to be some of the most potent modulators of lipid metabolism among amino acids. It has been demonstrated that these amino acids have an increasing effect on HDL-C and a decreasing effect on VLDL-C. This in turn causes the changes in vascular endothelium lesions [Clarke et al., 2006; Geisel et al., 2003]. Contrary results were reported by Carnicer et al. [2007] in their experiment with the Apo-E mice. According to other studies, the elevated Hcy concentration was associated with stronger oxidative stress and weakening of the vascular endothelium [Clarke et al., 2006; De Bree et al., 2002]. On the other hand, experiments conducted by Lentz [2005] on the animal's models proved that hyperhomocysteinemia and endothelial dysfunction were accompanied by decreasing bioavailability of the endothelial nitrogen. As a result, an increased susceptibility to arterial thrombosis is observed as well as accelerated development of arteriosclerotic lesions [Lentz, 2005]. This in turn may suggest a correlation between an elevated Hcy level and a higher risk of cardiovascular diseases (CVD). The highest risk for CVD is observed with respect to subjects with the increased level of homocysteine, CRP protein and LDL cholesterol [Herrmann et al., 2004]. In view of the results obtained along with the author's own studies and aforementioned findings of other authors, it may be concluded that in a high methionine diet, a protective activity of folic acid against Hcy concentration in blood depends on its level in such a diet (in this experiment $r=-0.95$ ), the animal's model applied and duration of the experiment.

\section{Total cholesterol}

In this experiment, the addition of methionine to control group II had a significant effect on the increase $(\mathrm{p}<0.05)$ in the total cholesterol content in blood serum (of about $38 \%$ ), compared to the control group I. Only in groups III and IV, a trend was observed towards a decrease in the total cholesterol content due to the addition of the lowest dose of folic acid. The results obtained in this experiment are similar to those reported by Liu et al. [2013] as well as confirm findings reported by Bieżanowska-Kopeć \& Leszczyńska [2012] and Rizki et al. [2006]. Sharma et al. [2007], whose findings corroborate the correlation shown in this study, reported an increase in the level of TC in rats' blood. Similar results as in the present study were described by Velez-Carrasco et al. [2008] for apoE-deficient mice. Opposite results are, in turn, reported by Carnicer et al. [2007], according to whom, the total serum cholesterol increased in the folic acid-treated mice

TABLE 2. Effects of diet types including methionine and folic acid supplementation on body weight gain, homocysteine and serum lipids concentrations in rats.

\begin{tabular}{|c|c|c|c|c|c|c|c|}
\hline \multirow[b]{2}{*}{ Parameter } & \multicolumn{7}{|c|}{ Diet } \\
\hline & $\begin{array}{c}\text { I } \\
\text { control }\end{array}$ & $\begin{array}{c}\text { II } \\
\text { control with } \\
\text { methionine }\end{array}$ & $\begin{array}{c}\text { III } \\
2 \mathrm{mg} \text { folic } \\
\mathrm{acid} / \mathrm{kg}\end{array}$ & $\begin{array}{c}\text { IV } \\
4 \mathrm{mg} \text { folic } \\
\mathrm{acid} / \mathrm{kg}\end{array}$ & $\begin{array}{c}\mathrm{V} \\
8 \mathrm{mg} \text { folic } \\
\mathrm{acid} / \mathrm{kg}\end{array}$ & $\begin{array}{c}\mathrm{VI} \\
18 \mathrm{mg} \text { folic } \\
\mathrm{acid} / \mathrm{kg}\end{array}$ & $\begin{array}{c}\text { VII } \\
28 \mathrm{mg} \text { folic } \\
\mathrm{acid} / \mathrm{kg}\end{array}$ \\
\hline $\begin{array}{l}\text { Final body weight } \\
\text { (g) }\end{array}$ & $286.75 \pm 11.82^{c}$ & $214.11 \pm 22.97^{a}$ & $241.44 \pm 18.93^{b}$ & $237.08 \pm 11.74^{\mathrm{ab}}$ & $221.91 \pm 27.99^{\mathrm{ab}}$ & $217.26 \pm 13.94^{\mathrm{a}}$ & $221.79 \pm 15.59^{a b}$ \\
\hline $\begin{array}{l}\text { Body weight gain } \\
\text { (g) }\end{array}$ & $159.76 \pm 11.82^{c}$ & $86.78 \pm 22.97^{a}$ & $114.11 \pm 18.93^{b}$ & $109.92 \pm 11.74^{\mathrm{ab}}$ & $94.75 \pm 27.99^{\mathrm{ab}}$ & $89.59 \pm 13.94^{\mathrm{a}}$ & $94.46 \pm 15.59^{\mathrm{ab}}$ \\
\hline $\begin{array}{l}\text { Homocysteine } \\
(\mu \mathrm{mol} / \mathrm{L})\end{array}$ & $11.06 \pm 0.88^{\mathrm{a}}$ & $89.43 \pm 39.11^{\mathrm{cd}}$ & $117.32 \pm 56.79^{d}$ & $98.37 \pm 25.45^{\mathrm{cd}}$ & $72.72 \pm 18.19^{\mathrm{bc}}$ & $60.78 \pm 29.85^{\mathrm{bc}}$ & $37.23 \pm 20.20^{\mathrm{ab}}$ \\
\hline $\begin{array}{l}\text { Total cholesterol } \\
(\mathrm{mmol} / \mathrm{L})\end{array}$ & $1.68 \pm 0.44^{\mathrm{a}}$ & $2.32 \pm 0.40^{\mathrm{b}}$ & $2.15 \pm 0.21^{\mathrm{b}}$ & $2.12 \pm 0.32^{\mathrm{ab}}$ & $2.38 \pm 0.25^{b}$ & $2.28 \pm 0.35 b$ & $2.39 \pm 0.58^{b}$ \\
\hline $\begin{array}{l}\text { HDL-cholesterol } \\
(\mathrm{mmol} / \mathrm{L})\end{array}$ & $1.41 \pm 0.34^{\mathrm{a}}$ & $1.98 \pm 0.30^{\mathrm{b}}$ & $1.81 \pm 0.18^{b}$ & $1.76 \pm 0.19^{\mathrm{b}}$ & $2.00 \pm 0.18^{b}$ & $1.92 \pm 0.26^{\mathrm{b}}$ & $1.95 \pm 0.45^{\mathrm{b}}$ \\
\hline $\begin{array}{l}\text { LDL+VLDL- } \\
\text { cholesterol } \\
\text { (mmol/L) }\end{array}$ & $0.27 \pm 0.13^{\mathrm{a}}$ & $0.34 \pm 0.11^{\mathrm{ab}}$ & $0.34 \pm 0.14^{\mathrm{ab}}$ & $0.36 \pm 0.18^{\mathrm{ab}}$ & $0.37 \pm 0.12^{\mathrm{ab}}$ & $0.36 \pm 0,11^{\mathrm{ab}}$ & $0.45 \pm 0.15^{b}$ \\
\hline $\begin{array}{l}\text { Triacylglycerols } \\
(\mathrm{mmol} / \mathrm{L})\end{array}$ & $0.42 \pm 0.09^{\mathrm{ab}}$ & $0.47 \pm 0.13^{\mathrm{abc}}$ & $0.59 \pm 0.13^{c}$ & $0.52 \pm 0.09^{\mathrm{bc}}$ & $0.46 \pm 0.09^{\mathrm{ab}}$ & $0.39 \pm 0.08^{\mathrm{a}}$ & $0.35 \pm 0.08^{\mathrm{a}}$ \\
\hline
\end{tabular}

Explanatory notes: *Values are presented as mean value \pm standard deviation $(n=6)$. The values denoted with the same letters do not differ statistically significantly at $\mathrm{p} \leq 0.05$. 
( $75 \mu \mathrm{g} / \mathrm{kg} /$ day). At the same time, a decrease in serum apoB concentrations indicates that the apoB containing particles of folic acid-treated mice carried more cholesterol. This effect was more pronounced in VLDL than in LDL particles.

\section{HDL cholesterol level}

The obtained results showed a significant increase $(p<0.05)$ of about $40 \%$ in the content of HDL cholesterol in blood serum of rats fed the high methionine diet compared to the control group. With regard to the methionine-supplemented group (II), the folic acid addition had no significant impact on changes in the value of this parameter. The results obtained in this study and these shown in other studies [Bieżanowska-Kopeć \& Leszczyńska, 2012] provide evidence that there is a positive correlation between the methionine supply and an increase in the HDL cholesterol. This, in turn, may acknowledge a positive methionine influence on lipid metabolism and, in consequence, may attenuate a risk of atherosclerosis.

The protective activity of high-density lipoproteins (HDL) against vascular diseases comes from the fact that they act as a go-between in reverse cholesterol transport [Navab et al., 2005]. These lipoproteins participate in cholesterol transport from peripheral tissues to the liver and affect to the greatest extent the total cholesterol content in this organ [Navab et al., 2005]. Clinical studies conducted in a group of patients with coronary artery disease showed a negative correlation between Hcy concentration and HDL cholesterol [Liao et al., 2006]. These results have been supported by findings obtained by Bieżanowska-Kopeć \& Leszczyńska [2012], and Oda et al. [1991]. However, they contrasted with results reported by other authors [Carnicer et al., 2007; Sharma et al., 2007; Velez-Carrasco et al. 2008].

\section{LDL+VLDL cholesterol level}

The folic acid supplementation of animals diet (2$-28 \mathrm{mg} / \mathrm{kg}$ the diet) had no impact $(\mathrm{p}>0.05)$ on the level of the LDL+VLDL. The serum of the rats administered the high methionine diet containing the highest dose of folic acid (group VII) had significantly more $(\mathrm{p}<0.05)$ LDL+VLDL cholesterol compared to the control group I, the increase being about $67 \%$.

In this experiment, methionine addition to the diet in the control group II had no significant effect $(p>0.05)$ on the level of the LDL+VLDL cholesterol fraction; only an ascending tendency was observed (Table 2). Low density lipoproteins are responsible for the transport of cholesterol to body cells; under the appropriate conditions it adheres to the intima cells of the artery vessel gradually forming the atherosclerotic plaque [Liu et al., 2008]. The increased LDL cholesterol level is the main risk factor for cardiovascular diseases [Urban, 2007]. As Bieżanowska-Kopeć \& Leszczyńska [2012] proved in their experiment, the methionine-supplemented diet did not noticeably change the level of LDL+VLDL cholesterol fraction in the rats' serum. Moundras et al. [1995], proved that the content of LDL cholesterol in blood serum was higher when the animals were provided a diet supplemented with a lower methionine dose; whereas higher doses of this amino acid led to a substantial decrease in this cholesterol fraction. This contrasts with findings reported by Sharma et al. [2007]. The addition of folic acid to the high methionine diet resulted in an ascending tendency observed for the level of LDL+VLDL cholesterol fraction; a similar effect was noted by Carnicer et al. [2007]. The authors observed a significant rise in this cholesterol fraction in the blood serum of the apoE mice due to the fact that their diet containing methionine was supplemented with folic acid. Methionine coupled with choline are the important precursors of phosphatydylocholine one of the main phospholipids occurring in the outer VLDL layer [Vance \& Vance, 1985]. Also, in their experiment Namekata et al. [2004] found higher concentrations of VLDL and/ or LDL cholesterol in $\mathrm{CBS}^{-/}$deficient mice compared to those determined in wild mice. On the other hand, the higher Hcy content resulting from methionine availability caused that the metabolic path of lipoproteins was partly improved. This may provide evidence for the anti-atherosclerotic character of methionine [Bieżanowska-Kopeć \& Leszczyńska, 2012].

\section{Triglycerides}

According to the present data, there was no statistically significant difference $(\mathrm{p}>0.05)$ in the TG level determined in the blood serum of the experimental animals fed the methionine-supplemented diet and the control diet I (Table 2). There was only a trend towards an increased TG value. Diet supplementation with folic acid had also no effect on significant changes $(p>0.05)$ in this parameter compared to the methionine control group; however, a negative correlation $(r=-0.94)$ was proved between the content of folic acid in a diet and the TG concentration in the serum of the experimental animals. There was only a trend towards an increased TG value.

As reviewed by Bieżanowska-Kopeć \& Leszczyńska [2012], an increase in the methionine supply is accompanied by a decrease in the TG level. In turn, Sharma et al. [2007] noted that when considering the methionine-supplemented diet of animals, extension of their feeding time resulted in a decrease in the TG concentration, even at little methionine dose. Opposite results were reported by Sharma et al. [2007] and Rizki et al. [2006]. The results presented in this paper suggest that folic acid and methionine concentration in blood as well as their participation in the process of methylation are associated with Hcy level and lipid metabolism. According to the literature, subjects receiving a diet high in folic acids as well as $\mathrm{B}_{6}$ and $\mathrm{B}_{12}$ vitamins, characterized simultaneously by a large content of these vitamins in blood serum, are less likely to suffer from cardiovascular diseases [Bønaa et al., 2006]. The liver is assumed to play a major role in the regulation of lipid metabolism. This organ absorbs the majority of amino acids and is also considered a major site of their metabolism. Excessive protein supply leads to catabolic transformation of amino acids; the formed alfa-ketoacids are used i.a. for the synthesis of fatty acids.

The results obtained in this paper and the data reported by other authors [Berg et al., 2005] suggest that hyperlipidemia may be associated with increased cell methylation. Methionine can be transformed into succinyl-CoA which participates in the metabolism of fatty acids. At the first stage of this process, methionine, via the adenylation process, is converted to S-adenosylmethionine (SAM), commonly used as a do- 
nor of methyl residues in a cell. Detaching methyl group and deadenylation results in forming homocysteine, which then may undergo the conversion to $\alpha$-ketobutyrate, the latter being converted first to propionyl-CoA by oxidative decarboxylation with the use of enzymatic complex and then to succinyl-CoA [Berg et al., 2005]. Hypermethylation associated with hyperhomocysteinemia (HHCY) is responsible for cholesterol biosynthesis in the liver and lipids' accumulation in tissues [Woo et al., 2005]. It seems that the acceleration of methylation increases the synthesis of phosphatidylcholine (PC) - a crucial phospholipid playing a key role in several metabolic paths in a cell [Ng et al., 2004]. PC is a methylated product of phosphatidylethanolamine (PE). According to Preynat et al. [2010], folic acid per se or together with vitamin $\mathrm{B}_{12}$ shows a tendency towards increasing the ratio of phosphatidylcholine (PC) to phosphatidylethanolamine (PE) [Preynat et al., 2010]. About 50\% of the plasma Hcy is involved in PC synthesis in the liver [Noga et al., 2003]; therefore, PC synthesis is recognized as a contact point between SAM and phospholipid metabolisms [Obeid \& Herrmann, 2009].

The results obtained in this study indicate that the supplementation of a high methionine diet with folic acid has a beneficial effect on the level of homocysteine; additionally, triglycerides are lowered to the base level.

\section{CONCLUSIONS}

The diet with high levels of methionine can increase the concentration of homocysteine as well as total cholesterol and HDL cholesterol. High doses of folic acid in the high methionine diet decreased homocysteine level of in the blood serum of experimental animals and had no effect on the lipoprotein profile. The levels of homocysteine and triglycerides in the serum of rats fed a high methionine diet, supplemented with the lowest dose of folic acid ( $2 \mathrm{mg} / \mathrm{kg}$ diet), showed a growing trend compared to animals fed the high methionine diet; and additionally were significantly higher compared to the animals administered the diet with higher doses of folic acid.

Supplementing the high methionine diet with folic acid, at the highest dose evaluated, resulted in a significant decrease in homocysteine levels and simultaneously in maintaining the favorable lipid profile parameters, obtained by the intake of methionine.

\section{RESEARCH FUNDING}

The study was financed from means of the: Polish National Science Center Project. No. DEC-2011/03/D/NZ9/05560.

\section{CONFLICT OF INTEREST}

Authors declare no conflict of interest.

\section{REFERENCES}

1. Berg J.M., Tymoczko J.L., Stryer L., Biochemistry. 2005, PWN Warszawa, Poland (in Polish).
2. Bieżanowska-Kopeć R., Leszczyńska T., The effect of the addition of methionine to the AIN-93G semi-synthetic diet on the levels of homocysteine and lipids in experimental rats. J. Nutr. Health Aging, 2012, 16, 395-400.

3. Bieżanowska-Kopeć R., Nosek M., Pisulewski P.M., Effect of graded dietary levels of folic acid, vitamin $\mathrm{B}_{12}$ and vitamin $\mathrm{B}_{6}$ on serum homocysteine concentrations in rats fed semi-purified diets. Ann. Nutr. Metabol., 2007, 51(Suppl 1), 264.

4. Bønaa K.H., Njølstad I., Ueland P.M., Schirmer H., Tverdal A., Steigen T., Wang H., Nordrehaug J.E., Arnesen E., Rasmussen K., Homocysteine lowering and cardiovascular events after acute myocardial infarction. N. Engl. Med., 2006, 354, 1578-1588.

5. Carnicer R., Navarro M.A., Arbonés-Mainar J.M., Acín S., Guzmán M.A., Surra J.C., Arnal C., De Las Heras M., Blanco-Vaca F., Osada J., Folic acid supplementation delays atherosclerotic lesion development in apoE-deficient mice. Life Sci. J., 2007, 80, 638-643.

6. Chien K.L., Hsu H.C., Sung F.C., Su T.C., Chen M.F., Lee Y.T., Metabolic syndrome as a risk factor for coronary heart disease and stroke: An 11-year prospective cohort in Taiwan community. Atherosclerosis, 2007, 194, 214-221.

7. Clarke Z.L., Moat S.J., Miller A.L., Randall M.D., Lewis M.J., Lang D., Differential effects of low and high dose folic acid on endothelial dysfunction in a murine model of mild hyperhomocysteinaemia. Eur. J. Pharmacol., 2006, 551, 92-97.

8. De Bree A., Verschuren W.M.M., Kromhout D., Kluijtmans L.A.J., Blom H.J., Homocysteine determinants and the evidence to what extent homocysteine determines the risk of coronary heart disease. Pharmacol. Rev., 2002, 54, 599-618.

9. Geisel J., Hennen B., Hübner U., Knapp J.P., Herrmann W., The impact of hyperhomocysteinemia as a cardiovascular risk factor in the prediction of coronary heart disease. Clin. Chem. Lab. Med., 2003, 41, 1513-1517.

10. Hainaut P., Jaumotte C., Verhelst D., Wallemacq P., Gala J.-C., Lavenne E., Heusterspreute M., Zech F., Moriau M., Hyperhomocysteinemia and venous thromboembolism: a risk factor more prevalent in the elderly and in idiopathic cases. Thromb. Res., 2002, 106, 121-125.

11. Herrmann W., Obeid R., Hübner U., Jouma M., Geisel J., Homocysteine in relation to $\mathrm{C}$-reactive protein and low-density lipoprotein cholesterol in assessment of cardiovascular risk. Cell Mol. Biol. (Noisy-legrand), 2004, 50, 895-901.

12. Karakuła H., Opolska A., Kowal A., Domański M., Płotka A., Perzyński J., Does diet affect our mood? The significance of folic acid and homocysteine. Pol. Merk. Lek., 2009, 26, 136-141 (in Polish).

13. Lentz S.R., Mechanisms of homocysteine-induced atherothrombosis. J. Thromb. Haemost., 2005, 3, 1646-1654.

14. Liao D., Tan H., Hui R., Li Z., Jiang X., Gaubatz J., Yang F., Durante W., Chan L., Schafer A.I., Pownall H.J., Yang X., Wang H., Hyperhomocysteinemia decreases circulating high-density lipoprotein by inhibiting apolipoprotein A-I Protein synthesis and enhancing HDL cholesterol clearance. Circ. Res., 2006, 99, 598-606.

15. Liu C., Wang Q., Guo H., Xia M., Yuan Q., Hu Y., Zhu H., Hou M., Ma J., Tang Z., Ling W., Plasma S-Adenosylhomocysteine is a better biomarker of atherosclerosis than homocysteine in apolipoprotein E-deficient mice fed high dietary methionine. J. Nutr., 2008, 138, 311-315. 
16. Liu D., Gao W., Liang E., Wang S., Lin W., Zhang W., Jia Q., Guo R., Zhang J., Effects of allicin on hyperhomocysteinemia-induced experimental vascular endothelial dysfunction. Eur. J. Pharmacol., 2013, 714, 163-169.

17. Moundras C., Remesy C., Levrat M., Demigne C., Methionine deficiency in rats fed soy protein induces hypercholesterolemia and potentiates lipoprotein susceptibility to peroxidation. Metabolism, 1995, 44, 1146-1152.

18. Namekata K., Enokido Y., Ishii I., Nagai Y., Harada T., Kimura H., Abnormal lipid metabolism in cystathionine beta-synthase-deficient mice, an animal model for hyperhomocysteinemia. J. Biol. Chem., 2004, 279, 52961-52969.

19. Navab M., Anantharamaiah G.M., Reddy S.T., Van Lenten B.J., Wagner A.C., Hama S., Hough G., Bachini E., Garber D.W., Mishra V.K., Palgunachari M.N., Fogelman A.M., An oral apoJ peptide renders HDL antiinflammatory in mice and monkeys and dramatically reduces atherosclerosis in apolipoprotein E-null mice. Arterioscler. Thromb. Vasc. Biol., 2005, 25, 1932-1937.

20. Ng M.N., Kitos T.E., Cornell R.B., Contribution of lipid second messengers to the regulation of phosphatidylcholine synthesis during cell cycle re-entry. Biochim. Biophys. Acta, 2004, 1686, 85-99.

21. Noga A.A., Stead L.M., Zhao Y., Brosnan M.E., Brosnan J.T., Vance D.E., Plasma homocysteine is regulated by phospholipid methylation. J. Biol. Chem., 2003, 278, 5952-5955.

22. Obeid R., Herrmann W., Homocysteine and lipids: S-Adenosyl methionine as a key intermediate. FEBS Letters, 2009, 583, $1215-1225$.

23. Oda H., Functions of sulfur-containing amino acids in lipid metabolism. J. Nutr., 2006, 136, 16665-16695.

24. Oda H., Fukui H., Hitomi Y., Yoshida A., Alteration of serum lipoprotein metabolism by polychlorinated biphenyls and methionine in rats fed a soybean protein diet. J. Nutr., 1991, 121, 925-933.

25. Orzechowska-Pawiłojć A., Lewczuk A., Sworczak K., The influence of thyroid hormones on homocysteine and atherosclerotic vascular disease. Pol. J. Endoc., 2005, 56, 194-202 (in Polish; English abstract).

26. Preynat A., Lapierre H., Thivierge M.C., Palin M.F., Cardinault N., Matte J.J., Desrochers A., Girard C.L., Effects of supplementary folic acid and vitamin $\mathrm{B}_{12}$ on hepatic metabolism of dairy cows according to methionine supply. J. Dairy Sci., 2010, 93, 2130-2142.
27. Reeves P.G., Nielsen F.H., Fahey G.C., AIN-93 purified diets for laboratory rodents: Final Report of the American Institute of Nutrition Ad Hoc Writing Committee on the Reformulation of the AIN-76A rodent diet. J. Nutr., 1993, 123, 1939-1951.

28. Refsum H., Smith A.D., Ueland P.M., Nexo E., Clarke R., McPartlin J., Johnston C., Engbaek F., Schneede J., Mcpartlin C., Scott J.M., Facts and recommendations about total homocysteine determinations: an expert opinion. Clin. Chem., 2004, 50, 3-32.

29. Rizki G., Arnaboldi L., Gabrielli B., Yan J., Lee G.S., Ng R.K., Turner S.M., Badger T.M., Pitas R.E., Maher J.J., Mice fed a lipogenic methionine-choline-deficient diet develop hypermetabolism coincident with hepatic suppression of SCD-1. J. Lipid Res., 2006, 47, 2280-2290.

30. Selhub J., Public health significance of elevated homocysteine. Food Nutr. Bull., 2008, 29(2 Suppl.), S116-S125.

31. Sharma M., Rai S.K., Tiwari M., Chandra R., Effect of hiperhomocysteinemia on cardiovascular risk factors and initiation of atherosclerosis in Wistar rats. Eur. J. Pharmacol., 2007, 574, 49-60.

32. Sierakowska-Fijałek A., Baj Z., Kaczmarek P., Stępień M., Rysz J., Estimation of relation between homocysteine concentration and selected lipid parameters and adhesion molecules concentration in children with atherosclerosis risk factors. Pol. Merk. Lek., 2008, 25, 356-360 (in Polish).

33. Urban M., Atherosclerosis in children and adolescents. 2007, in: Pediatrics - What's New? (ed. E. Otto-Buczkowska). Cornetis sp. z o.o., Wrocław, pp. 302-312 (in Polish).

34. Vance J.E., Vance D.E., The role of phosphatidylcholine biosynthesis in the secretion of lipoproteins from hepatocytes. Can. J. Biochem. Cell Biol., 1985, 63, 870-881.

35. Velez-Carrasco W., Merkel M., Twiss Ch.O., Smith J.D., Dietary methionine effects on plasma homocysteine and HDL metabolism in mice. J. Nutr. Biochem., 2008, 19, 362-370.

36. Williams K.T., Schalinske K.L., Homocysteine metabolism and its relation to health and disease. Biofactors, 2010, 36, 19-24.

37. WHO, [http://www.who.int/mediacentre/factsheets/fs317/en/].

38. Woo C.W., Siow Y.L., Pierce G.N., Choy P.C., Minuk G.Y., Mymin D., Karmin, O., Hyperhomocysteinemia induces hepatic cholesterol biosynthesis and lipid accumulation via activation of transcription factors. Am. J. Physiol. Endocrinol. Metab., 2005, 288, E1002-E1010.

Submitted: 15 January 2016. Revised: 25 June and 29 June 2016. Accepted: 25 July 2016. Published on-line: 21 November 2016. 